\title{
ESTIMATION OF GENETIC PARAMETERS OF LITTER WEIGHTS OF KHARI GOATS AND THEIR RESPONSE TOWARDS DIFFERENT NON- GENETIC FACTORS UNDER LOW INPUT MANAGEMENT SYSTEM IN NAWALPARASI, NEPAL
}

\author{
N. Bhattarai ${ }^{1}$, M.R. Kolachhapati ${ }^{2}$, N.R. Devkota ${ }^{1}$, U.C. Thakur ${ }^{3}$, and S.P. Neopane ${ }^{4}$ \\ ${ }^{1}$ Agriculture and Forestry University, Nepal, ${ }^{2}$ Institute of Agriculture and Animal Sciences, \\ Tribhuvan University, Nepal, ${ }^{3}$ Ministry of Forest and Soil Conservation, Nepal, ${ }^{4}$ Ministry of \\ Agriculture Devlopment, Nepal
}

\begin{abstract}
Accurate estimates of genetic parameters are important for genetic improvement in Khari goats. In this regard, altogether 1005 adult does of Khari goat in Deurali VDC, Nawalparasi were evaluated in terms of litter weight at birth (LWB) and litter weight at weaning (LWW) and their genetic parameters from February, 2012 to January 2015. Least square means (LSM) and standard errors of the mean (SEM) for these traits were determined with respect to some nongenetic factors such as altitude, season of conception, season of kidding, dam's parity, dam's size at conception, and birth type. Accordingly, Overall LSM \pm SE of LWB and LWW in present study were determined $3.97 \pm 0.06$ and $18.21 \pm 0.34 \mathrm{Kgs}$., respectively. Where, LWB did not differed significantly with altitude and dam's parity, however, it was significantly influenced $(p<0.001)$ by the season of conception, season of kidding, dam's size at conception, and birth type. Similarly, LWW was significantly varied with respect to altitude $(\mathrm{p}<0.01)$, season of conception $(<0.001)$, season of kidding $(<0.05)$, dam's parity $(<0.001)$, dam's size at conception $(<0.001)$, and birth type $(<0.001)$. Moderately high heritability estimates of LWB $(0.52 \pm 0.16)$ and LWW $(0.56 \pm 0.17)$ indicated that these traits were under the strong influence of additive genes and selection based the superiority of individual doe would be appropriate for successful genetic improvement. Highly significant positive genetic $\left(\mathrm{r}^{\mathrm{A}}=0.95\right)$ and phenotypic correlation $\left(\mathrm{r}^{\mathrm{P}}=0.91\right)$ between LWB and LWW suggested that selection for any of these trait would result in considerable positive change in other trait. More specifically, LWB can be used as a guide to select replacement does targeting to increased LWW within the herd.
\end{abstract}

Key words: Non-genetic factors, Kidding, Litter weight at birth, Litter weight at weaning.

\section{INTRODUCTION}

Nepal is enriched with more than 10 million heads of goats (MOAD, 2014) and endowed with four prominent indigenous breeds viz. Chyangra, Sinhal, Khari, and Terai (Kharel and Neopane, 1998). Goat production has become an alternative and lucrative livestock enterprise among the smallholder farmers having limited resources and low input supply capacity as reported by Amoah et al. (1996).

Reproductive efficiency is considered to be one of the important preconditions for achieving higher production and productivity from a flock of goats in any sort of environmental condition (Hoque et al., 2002). There is increasing demand of goat meat in Nepal that is being reflected by the importation of millions of goat heads from Tibet and India investing billions of Nepalese currency on fulfilling the country's meat demand. Khari goat, inhabiting in the mid-hill and hill ecology across the country, is well known for its prolificacy, twinning ability, adaptability in harsh climate and carcass quality. Reproductive efficiency is one of the important production parameter with the greatest impact on profitability in a commercial goat production system as argued by Browning et 
al. (2011). Dam traits such as litter weight at birth and litter weight at weaning are the important economic traits directly and closely associated with the production efficiency of goats.

LWB and LWW of Khari goats have been scarcely evaluated considering the major nongenetic factors such as altitude, season of conception, season of kidding, dam's parity, dam's size at conception, and birth type. Bhattarai (2007), Pandey (2007), Sapkota (2007), Shrestha (2002), and Neopane (1997) studied the effect of non-genetic factors on the litter traits of goats of different locations and reported to have significant influence of these factors on the traits. Houque et al. (2002) studied the effect of genetic group, parity, age of dam at kidding, weight of dam at breeding, season of conception and kidding, location etc. and suggested that litter weight was significantly affected by the age of dam at kidding $(p<0.01)$, weight of dam at service $(p<0.001)$ and parity $(p<0.001)$. In case of Khari goats, LWB and LWW are scarcely studied with respect to the non genetic factors and their genetic parameters including heritability estimates, genetic and phenotypic correlation are rarely estimated or outdated. Thus, present study mainly aimed at studying the effect of non-genetic factors on litter weight at birth and weaning of Nepalese Khari goat and estimating the genetic parameters of these traits.

\section{MATERIALS AND METHODS}

This study was conducted in the village goat herds of Deurali VDC, Nawalparasi, Nepal from February, 2012 to January 2015 covering two agro-ecological domains viz. Inner terai (lower altitude, ranging 300-700 masl) and hill (upper altitude, ranging 700-1100 masl). Data collected under this study were sub-classified on the basis of various non-genetic factors considered. Accordingly, season of conception and season of kidding were grouped into four sub-classes viz. Spring (February/March to April/May), Rainy (May/June to July/August), Autumn (August/September to October/November) and Winter (November/December to January/February); parity of dams into three sub-classes i.e. early ( $1^{\text {st }}$ and $2^{\text {nd }}$ parity), mid ( $3^{\text {rd }}$ to $6^{\text {th }}$ parity) and late $\left(7^{\text {th }}\right.$ and above parity), size of dams into three sub-classes i.e. small ( $\leq 22 \mathrm{~kg}$ live body weight), medium ( $>22$ to $\geq 32 \mathrm{~kg}$ live body weight) and large (>32 kg live body weight); and birth type in to three sub-classes i.e. single (does having $1 \mathrm{kid}$ at time), twins (does having 2 kids at a time) and triplet (does having 3 kids at a time). Birth weight of the litters of 1005 does was recorded within 24 hours of kidding and their subsequent weaning weight was recorded (in $\mathrm{Kg}$ ) at the age of 4 months.

Data were analyzed by 'Least Square Mixed Model and Maximum Likelihood Computer Program (LSMMML PC-2)' (Harvey, 1990). Least Square mean (LSM) and standard error of the mean (SEM) of litter weight at birth and weaning were determined using the following statistical model given by Henderson (1953). Significantly different means of LWB and LWW with respect to various sub-classes of non-genetic factors considered were compared using Duncan's Multiple Range Test (DMRT) computer software.

$\boldsymbol{Y}_{i j k l m n o}=\mu+a_{i}+b_{j}+c_{k}+d_{l}+f_{m}+g_{n}+e_{i j k l m n o}$

Where, $Y_{i j k l m n o}=$ adjusted mean for litter weight at birth and weaning of adult does.

$\mu=$ Pooled mean

$a_{i}$ is the effect of $\mathrm{i}^{\text {th }}$ altitude ( $\left.\mathrm{i}=1,2\right)$ : lower and upper.

$b_{j}$ is the effect of $\mathrm{j}^{\text {th }}$ season of conception $(\mathrm{j}=1,2,3,4)$; spring, rainy, autumn and winter.

$c_{k}$ is the effect of $\mathrm{k}^{\text {th }}$ season of kidding $(\mathrm{k}=1,2,3,4)$; spring, rainy, autumn and winter.

$d_{l}$ is the effect of $1^{\text {th }}$ number of parity of dams $(1=1,2,3)$; early, middle and late. 
$f_{m}$ is the effect of $m^{\text {th }}$ size of dams at conception $(m=1,2,3)$; small, medium and large.

$g_{n}$ is the effect of $\mathrm{n}^{\text {th }}$ type of birth $(\mathrm{n}=1,2,3)$; single, twins and triplets.

$e_{i j k l m n o}=$ is the random element (residual effect) assumed to be normally and independently distributed.

Besides, sire was taken as random (genetic) factor to estimate the genetic parameters (heritability estimates) of LWB and LWW and assessing the genotypic and phenotypic correlation between two traits. Following statistical model given by Henderson (1953) was used to estimate the genetic parameters and data were analyzed using LSMMML PC-2 by Harvey (1990).

$Y_{i j}=\mu+S_{i}+e_{i j}$

Where, $\mathrm{Y}_{i j}=$ Heritability estimates of the body weight and morphological traits of kids at different stages of growth.

$\mu=$ the overall population mean

$\mathrm{s}_{i}=$ random effect of $\mathrm{i}^{\text {th }}$ Sire $(\mathrm{i}=1,2$,

$\mathrm{e} i j=$ random error or residual effect- is the random (residual) element assumed to be normally \& independently distributed.

\section{RESULTS AND DISCUSSION}

\section{Least Square Mean of LWB and LWW}

The overall least square mean and standard error of LWB and LWW in present study were determined 3.97 \pm 0.06 and 18.21 $\pm 0.34 \mathrm{Kgs}$., respectively (Table 1). LWB of Khari goats in this study was at par with findings of Bhattarai (2007) and Neopane (1997) who reported the LWB of Terai and Hill goats in eastern Nepal as $3.41 \mathrm{~kg}$ and $3.38 \mathrm{~kg}$, respectively. However LWW of goats in both studies was too much lower as compared to the findings of present study. Shrestha (2002) also studied the effect of environmental factors on litter weight at birth and weaning of goats in mid-western Terai region of Nepal and reported lower values of LWB $(2.51 \mathrm{~kg})$ and LWW (16.11 kg), respectively. In contrary, Constantinou (1989) studied the genetic and environmental relationship and reported larger values of mean litter weight at birth and weaning (i.e. $8.8 \pm 2.6 \mathrm{~kg}$ and $32.7 \pm 13.4 \mathrm{~kg}$, respectively).

\section{Effect of Altitude}

Results of present study revealed that LWB did not differ significantly with respect to altitude. However, there was significant influence $(p<0.01)$ of altitude with respect to LWW (Table 1). Accordingly, LWB and LWW at birth and weaning were higher for the does reared lower altitude as compared to those in upper altitude. Sapkota (2007) compared the litter size at birth and weaning of four different districts including Udaypur, Siraha, Chitwan and Tanahun representing varying level of altitude and reported to have significant influence of location on litter weight at birth and litter weight at weaning. Higher values of LWB and LWW for the does reared at lower altitude might be due to the better management (Devendra and Marca, 1983) of the does during conception and subsequent kidding, as there was smaller size of herd per household in lower altitude.

\section{Effect of Season of conception and Kidding}

Findings also suggested that season of conception and kidding had significant effect $(\mathrm{p}<0.001)$ on LWB and LWW (Table 1). Accordingly, LWB was higher with does which conceived at rainy season (4.20 \pm 0.07$)$ and kidded at spring season $(4.18 \pm 0.07 \mathrm{~kg})$, respectively. Litter weight at birth 
depends on the amount of nutrition consumed by the doe especially at the last trimester. This finding also supported by the finding of Otuma $(2004,2006)$ for pure West African Dwarf goats strains of Savannah eco-zone of Nigeria that varied in weights along the season of rearing. Thus, higher LWB for the does conceived during rainy season might be due to the availability of high lustrous and nutritious forage/fodder during gestation and subsequently kidded during late winter or early spring season compared to other seasons of conception and kidding as reported by Paul et al. (2014), Journal \& North (2013), Nikhiala (2013) and Amoah et al. (1996). This reflected that natural grazing supplied enough nutrients to the does to meet the requirements for conception and kidding in gave birth to heavier litters during parturition as suggested by Nikhiala (2013).

On the other hand, LWW in present study was reported to be higher for the does that conceived during rainy season and kidded during winter as compared to those conceived and kidded during rest of the seasons (Table 1). Higher LWW of the does that conceived in rainy season might be due to significantly high and strong positive genetic and phenotypic correlation between LWB and LWW of the does in presented study as reflected in Table 2. Litter weight at weaning also depends on the favorable environment (including feeding) when the kid was born (Devendra and Marca, 1983). In this regard, the reason behind higher LWW for the does kidded during winter might be availability of nutritious and tender tree fodders/forages during subsequent spring season (Nikhiala, 2013) that might have helped lactating does to enhance mammary functions and produce more milk (Baldi et al., 2008) to nourish the young kids resulting higher weight of litters at the age of weaning.

\section{Effect of Dams' Parity}

Results of this study suggested that parity of dams did not have significant influence on LWB, whereas, the trait was significantly influenced $(p<0.001)$ by the effect of dams parity (Table 1$)$. Accordingly, LWW was higher for the does of, (and not significant difference between), mid as compared to that of early parity and tended to decline for the does of late parity. However, Browning et al. (2011) reported that LWW was higher for four year of doe in comparison to two or six years plus does. Higher LWW of the does at mid parity might be due to the fact that the does have been physiologically mature with during middle parity i.e. $3^{\text {rd }}$ to $6^{\text {th }}$ (Taye et al. 2011) decreased for late parity does due to degeneration of reproductive system (Deribe et al., 2014).

\section{Effect of Dams' Size at Conception}

Size of dams was an important source of variation $(\mathrm{p}<0.001)$ with respect to LWB and LWW (Table 1). Accordingly, LWB and LWW were recorded higher for the does having larger body size as compared to middle and smaller does. Present finding was similar to the result of Browning et al. (2011) and also supported by the findings of (Snyman, 2010) who reported that increase in the weight of does at the time of conception significantly improved the litter size and litter weight of does.

\section{Effect of Birth Type}

LWB and LWW of the does in this study were significantly influenced $(p<0.001)$ by birth type (Table 1). Accordingly, LWB and LWW were higher for the does having triplets $(5.51 \mathrm{~kg}$ and $25.11 \mathrm{~kg}$, respectively) as compared to those having single and twin kids. However, there were very fewer numbers $(\sim 1 \%)$ of does having triplets in this study. The finding of present study was similar to the result reported by Browning et al. (2011). 
Table 1. Effect of non-genetic factors on litter weight (in Kg.) at birth and weaning of Khari does in Nawalparasi, Nepal

\begin{tabular}{|c|c|c|c|}
\hline Fixed Factors & No. & LWB (LS mean \pm SEM) & LWW $($ LS mean \pm SEM $)$ \\
\hline Overall & 1005 & $3.97 \pm 0.06$ & $18.21 \pm 0.34$ \\
\hline Altitude & & NS & $* *$ \\
\hline Lower & 135 & $3.97 \pm 0.07$ & $18.64 \pm 0.38^{\mathrm{a}}$ \\
\hline Upper & 870 & $3.96 \pm 0.06$ & $17.78 \pm 0.34^{\mathrm{b}}$ \\
\hline Season of Conception & & $* * *$ & $* * *$ \\
\hline Spring & 77 & $3.97 \pm 0.08^{\mathrm{ab}}$ & $17.21 \pm 0.46^{\mathrm{c}}$ \\
\hline Rainy & 342 & $4.20 \pm 0.07^{\mathrm{a}}$ & $19.36 \pm 0.37^{\mathrm{a}}$ \\
\hline Autumn & 568 & $4.06 \pm 0.07^{\mathrm{ab}}$ & $18.87 \pm 0.38^{\mathrm{b}}$ \\
\hline Winter & 18 & $3.64 \pm 0.13^{\mathrm{b}}$ & $17.40 \pm 0.72^{\mathrm{c}}$ \\
\hline Season of Kidding & & $* * *$ & * \\
\hline Spring & 421 & $4.18 \pm 0.07^{\mathrm{a}}$ & $18.67 \pm 0.40^{\mathrm{a}}$ \\
\hline Rainy & 22 & $3.59 \pm 0.12^{\mathrm{b}}$ & $17.65 \pm 0.65^{b}$ \\
\hline Autumn & 254 & $3.99 \pm 0.07^{\mathrm{ab}}$ & $17.78 \pm 0.41^{\mathrm{b}}$ \\
\hline Winter & 307 & $4.11 \pm 0.07^{\mathrm{a}}$ & $18.74 \pm 0.40^{\mathrm{a}}$ \\
\hline Parity & & NS & $* * *$ \\
\hline Early $\left(1^{\text {st }}\right.$ and $\left.2^{\text {nd }}\right)$ & 381 & $3.98 \pm 0.07$ & $17.50 \pm 0.36^{\mathrm{b}}$ \\
\hline Middle $\left(3^{\text {rd }}\right.$ to $\left.6^{\text {th }}\right)$ & 478 & $3.99 \pm 0.07$ & $18.58 \pm 0.36^{\mathrm{a}}$ \\
\hline Late $\left(>7^{\text {th }}\right)$ & 146 & $3.93 \pm 0.07$ & $18.54 \pm 0.39^{a}$ \\
\hline Size of Dams & & $* * *$ & $* * *$ \\
\hline Small & 212 & $3.77 \pm 0.07^{\mathrm{b}}$ & $17.12 \pm 0.40^{\mathrm{c}}$ \\
\hline Medium & 656 & $3.92 \pm 0.06^{\mathrm{b}}$ & $17.99 \pm 0.35^{\mathrm{b}}$ \\
\hline Large & 137 & $4.21 \pm 0.07^{\mathrm{a}}$ & $19.51 \pm 0.38^{\mathrm{a}}$ \\
\hline Birth Type & & $* * *$ & $* * *$ \\
\hline Single & 761 & $2.24 \pm 0.04^{\mathrm{c}}$ & $10.26 \pm 0.23^{c}$ \\
\hline Twins & 233 & $4.16 \pm 0.05^{\mathrm{b}}$ & $19.26 \pm 0.27^{b}$ \\
\hline Triplets & 11 & $5.51 \pm 0.15^{\mathrm{a}}$ & $25.11 \pm 0.84^{\mathrm{a}}$ \\
\hline $\mathrm{CV}$ & & $16.68 \%$ & $20.86 \%$ \\
\hline
\end{tabular}

Note: LWB: Litter weight at birth; LWW: Litter weight at weaning; *: Significant at 5\% level $(\mathrm{P}<0.05)$; **: Significant at 1\% level $(\mathrm{P}<0.01)$; ${ }^{* * *}$ : Significant at $0.1 \%$ level $(\mathrm{P}<0.001)$; NS: Non-significant at $5 \%$ level ( $\mathrm{P} \geq 0.05)$; Means, within an effect, with the different superscript are significantly different; LS mean: Least square means; SEM: Standard error of Means; No: Number of observations, Figures with different superscripts on right up are significantly different.

\section{Estimation of genetic parameters}

Heritability estimates, genetic correlation and phenotypic correlation of LWB and LWW were estimated for the adult does of Khari goats under this study. The findings are discussed accordingly, hereunder. 


\section{Heritability estimates}

Results of this study revealed that the litter weight at birth and weaning were medium heritable traits (Table 2). Heritability estimates of LWB (0.52) and LWW (0.56) indicated that variation in these traits within the Khari goat flock were more influenced by genetically as compared to environmental influences. Slightly lower value of heritability estimates of LWB $(\mathrm{h} 2=0.44)$ and higher value of LWW (h2=0.66) was reported by Neopane (1997) while estimating the genetic parameters of Khari goats in eastern region of Nepal. Moderately high heritability estimates of LWB and LWW in this study indicated that genetic improvement on these traits could be achieved by direct selection through the weights of litters measured at birth and weaning as suggested by Journal \& North (2013).

\section{Genetic and phenotypic correlation}

Finding revealed that there was highly significant, strong positive genetic and phenotypic association between litter weight at birth and weaning (Table 2). Genetic and phenotypic correlation coefficients $\left(r^{\mathrm{A}}\right.$ and $\left.\mathrm{r}^{\mathrm{P}}\right)$ between LWB and LWW were 0.95 and 0.91 , respectively. Greater value of genetic correlation coefficient $\left(\mathrm{r}^{\mathrm{A}}\right)$ as compared to that of phenotypic correlation $\left(\mathrm{r}^{\mathrm{P}}\right)$ indicated that LWB and LWW, in this study, is largely a factor affected by the superiority of genotype or the breed itself, than environment as remarked by Journal \& North (2013) and LWB can be used guide to select replacements flock to increase the LWW of the does as suggested by Haricharan et al. (1987)

It was concluded in that study that birth weight can be used as a good guide to select replacements to increase the weaning and yearling weight of those breeds. Ali (1980) observed that the phenotypic correlation between birth weight and weights of the 1st, 4th, 8th and 13th weeks of age declined rapidly with increase in age in both males and females. The results obtained in this study suggest that selection to increase the 12-week weight in the herd should be based on the body weight of the kids at 12-weeks of age.

Table 2. Heritability (Mean \pm SE; across the diagonal), genetic (above diagonal) and phenotypic (below diagonal) correlation of litter weight at birth and weaning of Khari goat kids in Nawalparasi, Nepal.

\begin{tabular}{lccc}
\hline Parameter estimated & LWB & LWW & No. \\
\hline LWB & $0.52 \pm 0.16$ & $0.95^{* * *}$ & \multirow{2}{*}{1005} \\
LWW & $0.91 * * *$ & $0.56 \pm 0.17$ & \\
\hline
\end{tabular}

Note: LSB: Litter size at birth; LSW: Litter size at weaning; ***: Significant at $0.1 \%$ level $(\mathrm{P}<0.001)$; No.: Number of observations.

\section{CONCLUSION}

The results of this study indicated that the non-genetic factors such as altitude, season of conception, season of kidding dams parity, dam's size at conception and birth type were the important sources of variation with respect to litter weight at birth and weaning (except the altitude and parity on LWB). Significant influence of non-genetic factors on the litter weight at birth and weaning indicated that there is wider scope bringing improvement in these traits would be possible by providing due concentration on these factors. Specifically, study findings suggested that greater value LWB and LWW could be achieved by providing due care, management and optimum nutrition for the does from the beginning of conception or synchronizing the conception and kidding of does during the season when availability of highly nutritious fodder/forages and lustrous pasture in grazing land could be ensured. 
Besides, LWB and LWW could be increased by maintaining the optimum weight of does at the time of conception so as to ensure the optimum growth of fetus during gestation/pregnancy. Similarly, LWB and LWW could also be enhanced by selecting superior does with the potentiality of giving twins and triplets. Though, increased LWB and LWW increase in the size of litter, economics of feeding and management for the single, twins and triplets litters is important for reducing cost of per unit meat production, is yet to be studied.

Moderately high heritability estimates of LWB and LWW indicated that these traits are more influenced by genetic variations within the herd and attention must be given on selection of superior does within the herd for getting superior progenies with respect to these traits in future. Highly significant and strongly positive genetic and phenotypic association between LWB and LWW facilitated to conclude that LWB can be used as a guide to select replacement does for enhancing the weights of litter at weaning age.

\section{ACKNOWLEDGEMENTS}

The authors are grateful to Saroj Sapkota and Sunita Sanjyal, Scientists, NARC for their professional effort on analyzing data and critical review of this manuscript. Authors are equally grateful to Hari Krishna Panta, Chief of Planning Division/TU/IAAS, Sanepa, Lalitpur for his constant encouragement in preparation of this manuscript and publication of present work. Sincere thanks and heartfelt gratitude also goes to University Grant Commission (UGC), Sanothimi, Bhaktapur for the partial funding assistance while conducting present study in the field. Authors are also grateful to the farmers of commercial and smallholder farmers of Deurali VDC of Nawalparasi district. Support from the colleagues and administrative officials from Agriculture and Forestry University, Rampur, Chitwan are highly valued for their continuous cooperation during the study period.

\section{REFERENCES CITED}

Ali, S.Z., 1980. Relation to birth weight of kids to their post-natal growth in Black Bengal goats. Ind. Vet. J., 57, 1006-1008.

Amoah, E. a., S. Gelaye, P. Guthrie, \& C.E. Rexroad. 1996. Breeding Season and Aspects of Reproduction of Female Goats. Journal of Animal Science, 74(4), 723-728.

Baldi, A., F. Cheli, L. Pinotti, \& C. Pecorini. 2008. Nutrition in mammary gland health and lactation: advances over eight Biology of Lactation in Farm Animals meetings. Journal of Animal Science, 86(Supple.1), 3-9. http://doi.org/10.2527/jas.2007-0286.

Bhattarai, N. 2007. Morphometric variation and reproductive performance of local Terai goat under farmers' managed conditions in Siraha, Nepal. M.Sc (unpublished). Thesis. Institute of Agriculture and Animal Sciences, Rampur, Chitwan.

Browning, R., M.L. Leite-Browning \& M. Byars. 2011. Reproductive and health traits among Boer, Kiko, and Spanish meat goat does under humid, subtropical pasture conditions of the southeastern United States. Journal of Animal Science, 89(3), 648-660. http://doi.org/10.2527/ jas.2010-2930

Constantinou, A. 1989. Genetic and environmental relationship of body weight, milk yield and litter size in Damascus goats. Small Ruminant Research. 2: 163-174.

Devendra C. and B. Marca, 1983. Goat production in the tropics. Common-wealth Agricultural Bureaux, Franham House, UK. pp74-89.

Deribe, G., G. Abebe \& A. Tegegne. 2014. Non-Genetic Factors Influencing Reproductive Traits and Pre- Weaning Mortality of Lambs and Kids Under Smallholder Management, Southern Ethiopia. The Journal of Animal \& Plant Sciences, 24(2), 413-417. 
Harricharan, H., H. Ramlal, B. Lauckner \& B.L. Factors. 1987. Factors influencing the growth of intensively reared kids from birth to twelve weeks of age. Annales de zootechnie, 1987, 36 (4), pp.351-360.

Harvey, W.R.1990. Users' Guide for LSMLMW and MIXMDL. PC-2 Version. Mixed Model.

Henderson, C.R. 1953. Estimation of Variance and Covariance Components. Biometrics, Vol. 9, No. 2. pp. 226-252.

Hoque, M. A., M.R. Amin, \& D.H. Baik. 2002. Genetic and Non-genetic Causes of Variation in Gestation Length, Litter Size and Litter Weight in Goats. Asian-Aust. J. Anim. Sci, 15(6), $772-783$.

Journal, B., \& O.F. North. 2013. Genetic effects, relationships and heritability of some growth traits in Nigeria crossbreed goats, (Otuma 2003), 388-392. http://doi.org/10.5251/ abjna.2013.4.4.388.392

MOAD. 2014. Selected indicators of Nepalese Agriculture and Population. Agri-business promotion and Statistics Division (ABPSD), Ministry of Agriculture Development (MOAD), Singh Durbar, Kathmandu, Nepal.

Neopane, S.P. 1997. Genetics of productive traits in a Nepalese Hill goat flock. Ph.D. Thesis. University of London, UK. 278p.

Kharel, M and S.P. Neopane. 1998. Goat genetic resources. In: Proceedings of the $1^{\text {st }}$ National Workshop on Animal Genetic Resources Conservation and Genetic Improvement of Domesticated Animals in Nepal. (Editor: JNB Shrestha). Nepal Agricultural Research Council (NARC) from 11 to 13 April 1994, Pp 48-54, Kathmandu, P O Box 5459, NepalNikhiala, a M. A. 2013. Effect of season of birth and litter size on Taggar goat's production in western Sudan, 2 (April), 128-133.

Otuma, M. O. 2004. Influence of breeding designs and seasonal changes on growth of Nigerian goats and their crosses. Tropical journal of Animal Science 7(2) $109-116$.

Otuma, M. O. 2006. Study of Post-weaning growth of F1 and F2 backcrosses of goats managed on different humid tropical environment International Journal of Agriculture and Rural Development 7 (2) $48-51$.

Pandey, S.R. 2007. Effect of genetic groups on litter and dam traits of goat under the Western hill condition of Nepal. M.Sc. Thesis. Institute of Agriculture and Animal Sciences, Rampur, Chitwan.

Parajuli, A.K. 2012. Morphometric Characterization and Performance Evaluation of Hill Goat in Mid Hills of Nawalparasi District of Nepal. Thesis MSc. Institute of Agriculture and Animal Sciences, Rampur, Chitwan. 114p.

Paul, R. C., A. Rahman, S. Debnath, \& M. Khandoker. 2014. Evaluation of productive and reproductive performance of Black Bengal goat production, 104-111.

Sapkota, S. 2007. Comparative performances of goats representing eastern, central and western development regions of Nepal. Thesis MSc. Institute of Agriculture and Animal Sciences, Rampur, Chitwan. 138p.

Shrestha, Y.K. 2002. Study on production parameter of goat in mid-western Terai region of Nepal. M.Sc. Thesis (unpublished). Institute of Agriculture and Animal Sciences, Rampur, Chitwan.

Taye, M., G. Abebe, S. Gizaw, S. Lemma, A. Mekoya, and M. Tibbo. 2011. Reproductive performances and survival of Washara sheep under smallholder management systems in Yilmanadensa and Quarit districts, Hawassa, Ethiopia. J. Anim. Sci. and Veterinary Advances. 10:1158-1165. 